\title{
CONSTRUCTING CONSENSUS: DEVELOPING AN ADVANCED NURSING PRACTICE ROLE
}

\author{
Jill Wilkinson, RN, PhD, MCNA(NZ), Senior Lecturer, \\ School of Health \& Social Services, Massey University, Wellington
}

\begin{abstract}
Following the release of the Ministerial Taskforce on Nursing in August 1998 and the withdrawal of the New Zealand Nurses Organisation from the Taskforce membership, a 'decision-making' workshop was held to further advance nursing practice roles in New Zealand. Momentum about advanced nursing roles had been gathering spurred on by political reform and the research about established nursing practitioner and clinical nurse specialist roles overseas. This study uses a discourse analytical approach to trace the ongoing struggle between nursing groups for power to control the future of advanced nursing practice. The convergence of political discourses with those that were dominant in nursing during this period produced considerable tension, but eventually led to a consensus position concerning the location of a nurse practitioner role within the regulatory framework of the Nursing Council of New Zealand.
\end{abstract}

Key Words: Nurse practitioner, consensus, autonomy, unionism.

\section{Introduction}

Following the release of the Ministerial Taskforce on Nursing in August 1998, the struggle within nursing over the power to control its future persisted. Two dominant and conflicting discourses at play were autonomy and unionism and their convergence with the political discourses of this period continued to produce considerable tension. Eventually, a consensus position was reached and the advanced nursing practice role of nurse practitioner was placed within the regulatory framework of the Nursing Council of New Zealand (henceforth Nursing Council).

This article follows on from the previous discussion in this issue about the Ministerial Taskforce on Nursing, drawing from the same recent research project (Wilkinson, 2007). The discussion begins by introducing the international and national influences on the work of the Taskforce team. The journey towards a consensus position about advanced nursing practice in New Zealand was set in motion by an academically-led 'decision-making' workshop that was fundamentally at odds with union democratic practices. Looking back at these events is a reminder of the real effects discourses produce and the importance of positioning nursing collaboratively in ways that will enhance its full potential.

Wilkinson, J. (2008). Constructing consensus: Developing an advanced nursing practice role. Nursing Praxis in New Zealand, 24(3), 17-26. 
The research from which this article has been developed draws on a variety of texts chosen from published literature that illustrate particular discursive positions. Transcripts of interviews conducted with individuals who have been influential in the unfolding of the nurse practitioner role in New Zealand have also been used. Approval for the study was obtained from the Massey University Human Ethics Committee.

\section{A Gathering Momentum of Discussion}

Susan Jacobs (1999) described a gathering momentum of discussion within nursing circles about clinically focused advanced nursing practice in the eighteen months preceding the Taskforce work. A number of factors converged to give the discussions impetus (and these are discussed in detail by Jacobs, 1998):

- Announced in 1995, \$5 million would be made available from 1998 for clinically focused postregistration nursing education

- In 1996 the Nursing Council framework document for post registration nursing competencies and education began circulation

- During 1995-96 a position paper modelled on the United States (US) advanced practice roles of clinical nurse specialist and nurse practitioner was developed by Nurse Executives of New Zealand (NENZ)

- In 1997 a position paper by Nurse Educators in the Tertiary Sector (NETS) about post registration nursing education was written;
- On 12 May 1998 during the work of the Taskforce, the then Minister of Health announced an amendment to the Medicines Act 1981 that would enable nurse prescribing

- In early 1998 the Nursing Council decided that entry to the register would be by bachelor degree only.

These discussions and documents about advanced practice did not occur in isolation, but were informed by the international experience of nurse practitioners concerning their efficacy across a variety of settings (Bissinger, Allred, Arford, \& Bellig, 1997; Brown \& Grimes, 1995; Fall et al., 1997; Jones \& Clark, 1997; Shiell, Kenny, $\&$ Farnworth, 1993). This research evidence is cited in the Taskforce report and foregrounds the academic discourse drawn on to support the introduction of a nurse practitioner role for New Zealand.

International evidence published subsequent to the Taskforce was supportive of the contribution of nurse practitioners to health outcomes and carried significant weight with politicians and physicians in New Zealand, particularly as the debate over nurse prescribing intensified. In Foucauldian terms, the high value placed on research evidence, illustrates the power of a scientific discourse to produce a 'regime of truth'. Research "techniques and procedures are accorded value in the acquisition of truth" and makes it possible "to distinguish true and false statements" (Foucault, 1991, p. 73). Ultimately the nexus between technology and power produces what counts as true 
and, in this case, articulated with the academic discourse of particular nurses to further their argument for an advanced nursing practice role.

\section{Constructing Consensus}

In an effort to progress the issues raised in the Ministerial Taskforce on Nursing report, a three-day workshop hosted by the College of Nurses was held in Palmerston North in March 1999. The workshop aimed to develop guidelines that would address issues of nationally consistent titles; the level of education for advanced nursing practice; the location of prescribing authority; how advanced nursing roles would differ from medicine; and which body would do the credentialing. One hundred and thirty-five nurses attended from a broad cross-section of practice and policy areas, the majority of whom were New Zealand Nurses Organisation (NZNO) or College members (Smith, 1999). By then, tertiary institutions were starting to develop advanced nursing practice programmes and working parties on prescribing authority for nurses had been established. No nationally consistent title for advanced nursing practice had been decided upon and the situation prior to the Taskforce of a proliferation of nursing titles and roles continued. The Workshop proceedings summarised the issues the profession agreed upon and the issues around which some tension and disagreement remained ("Work in progress," 1999).

Referred to as a decision-making workshop (Jacobs, 1999; Smith, 1999; "Work in progress," 1999), NZNO stated the purpose of its participation was to "take information back to its members for discussion" (Cain, 1999, p. 27). Decisions, however, were voted on by those present and actioned as a result of the workshop. The following interview text highlights the discourses of autonomy and unionism that were fundamentally at odds with one another as one sought professional self-determination via dialogue and decision-making, and the other via consultation with members not present:

It was a College of Nurses hosted conference and it had a very loose agenda. Well, it had a very loose programme; it had a very clear agenda, which was to push in a certain direction around nurse practitioners. There were about 112 there if I recall correctly and there were four [staff] from NZNO ... In the first day there were these workshops, there were no papers, so a lot of the contextual stuff was missing from the discussions of those workshops. And we came back into plenary session and suddenly there was this call, "Well we'll vote on these things, ideas and concepts" to which [we] said, "We can't do this. This is not a decision-making body."

Jill: There were two lists; things that were agreed on and things that remained contentious.

We wouldn't have agreed. It's just not in fitting with the processes within our organisation. We would never; we have no authority ... as staff members to say that we would commit to a policy. It is not the way our organisation works (Interview with NZNO). 
The speaker suggests the College as host had pre-determined the direction the workshop would take. Consensus was sought by way of a vote, but making policy decisions based on the small number of nurses present was anathema to union democratic practices. All the same, the union perspective was not altogether overshadowed by the workshop and in fact, complemented discourses of autonomy in the following statement which identified remaining key challenges:

There is concern within the profession that nurses will be asked to provide an expanded service without reimbursement commensurate with the increased level of responsibility, the personal investment in education and the need for ongoing professional development which will be integral to advanced practice roles ... we need to clarify that advanced practice roles are not simply a less expensive substitution for medicine. Rather, advanced practice nursing is about providing some services more cheaply, providing others that are currently overlooked, and co-ordinating more effectively some of the fragmented care which is already provided ("Work in progress," 1999, p. 14).

Autonomy, in this statement, is evident in the desire to address a health agenda with an advanced practice role, but not without remuneration commensurate to the expanded service and personal investment in education. Of all statements contained in the proceedings document, this statement does reflect a consensus of the two previously conflicting positions. Determination to overcome differing positions and work together strategically did ensue during the coming year, although the increasing role and function of the Nursing Council remained problematic for the NZNO.

Considerable discussion at the decision-making workshop occurred about where the responsibility for credentialing an advanced practice role should lie, particularly in light of disagreement over this issue following the Taskforce report. The conference proceedings stated that "In general it was agreed that the Nursing Council should co-ordinate and manage the credentialing process with the professional organisations" ("Work in progress," 1999, p. 11). Those present also endorsed the continued refinement of the Nursing Council framework, guidelines and competencies for post-registration nursing education (Nursing Council of New Zealand [NCNZ], 1998). The rationale for the Council taking responsibility for credentialing has already been examined, but disquiet even among Council members remained:

[The Council had] taken on more of a leadership role in professional matters than you normally would ...no one would because everyone was fighting. Idecided that we were this wonderful neutral body that's pulled together from everywhere that shouldn't have an axe to grind, that therefore we would go and get the documents going like the advanced nurse practitioner and the advanced education model. And that no one else was doing it. In my heart of hearts, I know 
Nursing Council shouldn't have done it because it's not Nursing Council's role. Nursing Council is for public safety. I convinced myself that if we had those documents then the public would be safer. I knew that's Nursing Council's role - public safety, put people on the register, off the register - and the professional side was done by nursing organisations. But they weren't doing it, pure and simple and I make no apology for it (Interview with NCNZ).

The speaker in this text acknowledges that developing an advanced nursing practice role and education model was beyond the Nursing Council's jurisdiction, but justified its involvement on the grounds that 'no one else was doing it'. Characterising itself as 'this wonderful neutral body' suggests an impartiality that at best, is highly speculative. The semblance of neutrality in this instance was a powerful strategy to take 'a leadership role in professional matters' and overcome the divisions within nursing that were constraining the profession's development.

Reflecting on the role the Nursing Council undertook, the following participant recalls the divisions within nursing at the time and positions them specifically as a 'unionist stance' and a 'professional advocacy stance':

How did we arrive there [with the Nursing Council regulating the NPJ? ... To me it was a Council forum that really put a stake in the sand that we never re-visited. And it was one in Wellington, probably about five or six years ago [most likely October 1999], could even be longer. And at the time all this prescribing and NP work was starting the Council wanted to know if they should continue this work or if the professions would be the better place to locate it. At the time the profession was somewhat splintered between those who took a more unionist stance and those who took a more professional advocacy stance. The groups were not strong and the voice back to Council was, "You continue to manage and broker that for us". And it was never revisited. So the profession, albeit an unrepresentative, ad hoc, consultative voice that was present there ... gave the Council license to continue its work that way and to act as an agent that drew in the profession to advise $i t$, take the responsibility that was actually beyond its regulatory mandate (Interview with a nurse academic).

The speaker reiterates the idea from the previous interview text that because the groups were 'splintered', the Nursing Council, by default rather than design, took on regulation of the NP role. The terms 'broker' and 'agent' are used suggesting the Council could best represent the interests of nursing - a task that does normally fall to the professional organisations. Interestingly, the Nursing Council's "means of bringing power relations into being" (Foucault, 1983, p. 233) was to defer to the profession's wishes, but one could equally say, to take control at a time when the profession was most vulnerable. The decision was never 're-visited' and may well have related to the anticipated revision of 
the Nurses Act 1977 and the potential to include an advanced nursing role in new legislation.

Concern about the lack of preparedness of the Council to take on credentialing of an advanced role and bolstered by the ICN position on professional selfregulation, the NZNO invited the other nursing organisations to work together on a unified model where together they would do the credentialing for advanced nursing practice (see also Trim, 2004):

And at the end of the day there was a meeting between the College, the Nurse Execs and the NZNO and we agreed to a broad strategy for moving forward together and then later on the College of Mental of Health Nurses came in and the Council of Maori Nurses. What we worked on was drawing out the proposal where we [the professional organisations] would do the credentialing and we worked in great detail through the process: what ifs; how would we assess educational equivalence etc. And at the end of the weekend the working party invited ... the chair of the Nursing Council at that time, to the meeting and to hear our work and to give us some initial feedback and responses. She thought that what we were doing was great. Was very encouraging but she didn't think that Nursing Council could relinquish control of credentialing. We continued to work on a proposal but we really took out that we would do the credentialing but we would have oversight of the processes, criteria and application. And we presented that proposal to Nursing Council and Nursing Council couldn't accept it. But it was the opening ground for us to work on what eventuated as NPAC-NZ (Interview with NZNO).

The NZNO had developed considerable credentialing mechanism expertise through its own processes and remained optimistic about working collaboratively with the other nursing organisations to carry out the credentialing of advanced nursing practice, in lieu of the Council. A last ditch attempt, it failed to gain Council approval, yet formed the basis for an alternative structure to address the concerns of these organisations, the NZNO-led, Nurse Practitioner Advisory Council of New Zealand (NPAC-NZ). According to Trim $(2002$, p. 27), this committee, established in July 2002, was the "first major collaborative venture between the five organisations ... for the future development of the nurse practitioner model".

\section{Role Roll-out}

Following the election of a Labourled coalition government in 1999 the new Minister of Health bolstered the development of an advanced nursing practice role with considerable political sponsorship, envisioning nurse practitioners to be "ideally placed" to provide services under the newly developed PHC Strategy (Hon Annette King in Ministry of Health, 2002, p. iii). The Ministry of Health's Chief Nursing Advisor, Frances Hughes, the Nursing Council and Professor Jenny Carryer worked to develop a model for New Zealand, based on the research of Hughes on advanced nursing practice in the US and the international evidence in 
support of the role (Ministry of Health, 2002). A blend, based principally on the US model of nurse practitioner and clinical nurse specialist, was adapted for the New Zealand model, enabling nurses to be endorsed in their specialty at their chosen level of primary, secondary or tertiary care.

A joint statement released by the Nursing Council and Ministry of Health in May 2001, announced the new nursing qualification. The Nursing Council would formally regulate the role, set advanced nursing competencies, including those for prescribing, and monitor the masterate level education programmes (Ministry of Health, 2001). Following the launch of the document Nurse Practitioners in New Zealand in July 2002 by the Minister of Health, a series of road shows were held throughout the country to present information to health providers about how the role could be implemented (Hughes, 2003). The first nurse practitioner was credentialed in December 2001 ("First nurse practitioner appointed," 2002).

The introduction of the Employment Relations Act 2000 brought about important changes within the NZNO. The Act restored the role of unions nationally in promoting their members' collective employment interests and along with a change in leadership within the organisation, softened the NZNO's militant position to bring a renewed focus to the representation of professional issues. Successive position statements made by the NZNO on advanced nursing practice illustrate a shift towards acceptance of the Taskforce recommendations. For example, a statement made in 2000 , supported educational preparation at masterate level, stating that "Being an expert-by-experience in a specialty is not on its own sufficient for advanced nursing practice" (NZNO, 2000, para. 4). Recognition of the role in the statement, however, was to be by "professional self-regulation through the professional associations and not through statute" (para. 14). Following the announcement in October 2000 that the Nursing Council would regulate the role, the NZNO position statement was revised to state, as a matter of fact, the Council's role in regulation (NZNO, 2003).

Although the official NZNO position on the conditions for a nurse practitioner role began to align with that of the Nursing Council and Ministry of Health, considerable residual resistance amongst the membership is recorded in articles and letters to the editor in Kai Tiaki (see Pantano, 2003; Pepperell, 2003). A case in point is that of Marg Eckhoff, whose application for nurse practitioner endorsement was turned down twice because of problems with educational equivalency. She is quoted as saying:

I think there are a lot of academic nurses having a lot of say in the direction of the profession. I think they've lost the plot - lost contact with clinical nursing. It is the people on the ground who really understand and I feel those academic nurses are looking down on us. I'd like to say to them 'come and try my job for a while' (O’Connor, 2003a).

Echhoff later wrote to the editor of Kai Tiaki, overwhelmed by the 
support from New Zealand nurses and thanked those who had written to her and to the magazine (for example, Baillie, 2003). O'Connor (2003b, p. 13) summarises the common threads found in the articles and letters to Kai Tiaki:

that nurses who want to advance academically and those who want to remain in practice, learning through on-the-job study, should be equally valued; that nurses who have been working at an advanced level of practice for years, some of whom have been called NP, are feeling frustrated and disillusioned; that the NP role may create divisions within the profession; that those driving advanced nursing practice are out of touch with the reality of clinical practice.

These concerns of elitist education creating divisions within the profession are firmly embedded within the unionist discourse and were represented by the NZNO throughout the work of the Taskforce. These anxieties have resonance with the reaction to the introduction of comprehensive nursing education in the 1970s and the fear that hospital trained nurses would no longer be valued (Geoff Annals, CEO of NZNO in O'Connor, 2003b). As was the case at that time, discourses of autonomy and academia produced effects of domination achieved by the position of power held by those speaking and the institutions they represent (Foucault, 1990). Evidence of an incomplete shift from 'learning through onthe-job study' towards an academic preparation remains some thirty-five years later, raising questions about how embedded academic inquiry is to nursing practice.

\section{Conclusion}

This discussion has examined the clash of particular discourses as the construction of the nurse practitioner role became a struggle within nursing for power to control its future development. In the construction and recommendations of the Ministerial Taskforce on Nursing and in subsequent consensus development, discourses of autonomy partnered with those of academia and neoliberalism to exclude a unionist discourse and position the nurse practitioner within a state-sponsored regulatory framework.

Sarap (1996, p. 75) has to say of Foucault, "it is generally believed that he is not interested in who has power" and this discussion has dwelt on which discourse, rather than particular individuals, held power. As has always been so in nursing, however, an effect of individuals holding office across a number of closely related institutions facilitated the dominance of particular discourses in the construction of the nurse practitioner, those of academia and autonomy. These relationships were most evident in the membership of the Ministerial Taskforce on Nursing and continued through subsequent phases of role development.

Within a discipline as large as nursing, there will inevitably be competing discourses that position nursing as internally divided. While contained within nursing, these tensions can be generative and ultimately collaborative, but when aired outside of nursing 
the image of a unified profession is readily destroyed. The ever present temptation to retreat to the either/ or position of competing discourses tends to preclude the possibility that even contradictory discourses can be ascribed to simultaneously. A unified

\section{References}

voice would have been immensely more productive for nursing politics in New Zealand at the time: but also for the future, as nursing leaders collaboratively harness government objectives to improve access to health services and to further the professional aspirations of nursing.

Baillie, M. (2003). Practice nurse incensed at treatment of rural nurse. Kai Tiaki Nursing New Zealand, 9(4), 3-4.

Bissinger, R. L., Allred, C. A., Arford, P. H., \& Bellig, L. L. (1997). A cost-effectiveness analysis of neonatal nurse practitioners. Nursing Economics, 15(2), 92-100.

Brown, S., \& Grimes, D. (1995). A meta-analysis of nurse practitioners and midwives in primary care. Nursing Research, 44(6), 332-338.

Cain, M. (1999). Advancing nursing practice. Kai Tiaki Nursing New Zealand, 5(3), 27.

Employment Relations Act. (2000). New Zealand Government: Wellington.

Fall, M., Walters, S., Read, S., Deverill, M., Lutman, M., Milner, P., et al. (1997). An evaluation of a nurse-led ear care service in primary care: Benefits and costs. British Journal of General Practice, 47(424), 699-703.

First nurse practitioner appointed. (2002). Kai Tiaki Nursing New Zealand, 8(1), 7.

Foucault, M. (1983). The subject and power [Afterword]. In H. L. Dreyfus \& P. Rabinow (Eds.), Michael Foucault: Beyond structuralism and hermeneutics (2nd ed., pp. 208-226). Chicago: University of Chicago Press.

Foucault, M. (1990). The history of sexuality: An introduction. Volume One (R. Hurley, Trans.). New York: Vintage Books.

Foucault, M. (1991). The Foucault reader. London: Penguin Books.

Hughes, F. (2003, June). Nursing sector update (Report). Wellington: Ministry of Health.

Jacobs, S. (1998). Advanced nursing practice in New Zealand: 1998. Nursing Praxis in New Zealand, 13(3), 4-12.

Jacobs, S. (1999). Advanced nursing practice: Refining a New Zealand approach. Vision, 1(8), 24-26.

Jones, M. E., \& Clark, D. (1997). Increasing access to health care: A study of pediatric nurse practitioner outcomes in a school-based clinic. Journal of Nursing Care Quality, 11(4), 5360.

Ministry of Health. (2001, May 15). Joint statement from Nursing Council of New Zealand and Ministry of Health: New nurse practitioners will be a boost for health system. Retrieved July 23, 2003, from http:/ /www.moh.govt.nz/moh.nsf/c7ad5e032528c34c4c2566690076db9b/ e82d7db8d40df68ccc256a4d000d93df?OpenDocument

Ministry of Health. (2002). Nurse practitioners in New Zealand. Wellington: Author.

New Zealand Nurses Organisation. (2000). Advanced nursing practice: NZNO position statement. Wellington: Author.

New Zealand Nurses Organisation. (2003). Nurse practitioners in New Zealand: NZNO position statement. Wellington: Author.

Nurse Educators in the Tertiary Sector. (1997). Position statement: Post registration nursing education. Dunedin: Author. 


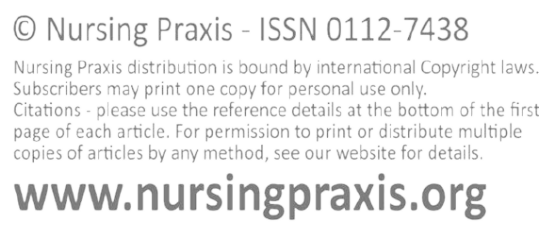

Nurses Act. (1977). New Zealand Government: Wellington.

Nursing Council of New Zealand. (1998). Framework, guidelines, and competencies for postregistration education. Wellington: Author.

O'Connor, T. (2003a). Relishing the challenges of rural nursing ... Marg Eckhoff. Kai Tiaki Nursing New Zealand, 9(2), 16-17.

O'Connor, T. (2003b). Why the angst about nurse practitioners? Kai Tiaki Nursing New Zealand, 9(6), 13-14.

Pantano, T. (2003). Loss of NP title causes demoralisation. Kai Tiaki Nursing New Zealand, 9(11), 20.

Pepperell, G. (2003). Former nurse practitioner disillusioned with nursing [Letter to the editor]. Kai Tiaki Nursing New Zealand, 9(4), 3.

Sarup, M. (1996). Identity, culture and the postmodern world. Edinburgh: Edinburgh University Press.

Shiell, A., Kenny, P., \& Farnworth, M. G. (1993). The role of the clinical nurse co-ordinator in the provision of cost-effective orthopaedic services for elderly people. Journal of Advanced Nursing, 18(9), 1424-1428.

Smith, T. (1999). Advanced nursing practice: A three-day decision making workshop. Nursing Praxis in New Zealand, 14(1), 58.

Trim, S. (2002). Developing the role of nurse practitioner. Kai Tiaki Nursing New Zealand, 8(4), 27.

Trim, S. (2004). Shaping the nurse practitioner model in New Zealand: Critical partnerships. Paper presented at the ICN Nurse Practitioner Conference, Netherlands.

Wilkinson, J. A. (2007). The New Zealand nurse practitioner polemic: A discourse analysis. Unpublished doctoral dissertation. Massey University, Wellington, NZ. Available from http:/ / hdl.handle.net/10179/533

Work in progress: Towards the development of guidelines for advanced nursing practice in New Zealand. (1999). Proceedings from the conference/workshop hosted by the College of Nurses Aotearoa, March 1 - 3, 1999.

\section{BACK ISSUES FOR SALE NURSING PRAXIS IN NEW ZEALAND}

We are offering a special discount to allow subscribers to complete their set of "Praxis" or to replace well worn issues.

Most, but not all issues are available - at $\$ 5.00$ each.

$10 \%$ discount for orders of $5-9$ issues

$20 \%$ discount for orders of 10 or more issues.

ORDER NOW!!!

Contact details are on the inside front cover 